\title{
MONITORAMENTO SAZONAL DA ATIVIDADE DE SEQUESTRO DO RADICAL LIVRE DPPH- DA ESPÉCIE CALOPHYLLUM BRASILIENSE CULTIVADA NO AMAPÁ
}

\author{
F. M. S. COSTA ${ }^{1}$, G. A. $\operatorname{SILVA}^{1}$ e D. C. SANTOS ${ }^{1}$ \\ ${ }^{1}$ Universidade do Estado do Amapá \\ E-mail para contato: fmanuelascosta@gmail.com
}

\begin{abstract}
RESUMO - O estudo de sazonalidade contribui para avaliação da variação do teor de ativos de plantas e sua influência na atividade biológica frente a diferentes variações ambientais durante o ano, sendo possível estabelecer o melhor período de coleta do material botânico para uso terapêutico. Desta forma o presente trabalho teve como objetivo o monitoramento sazonal da atividade de sequestro do radical livre DPPH • das cascas da espécie Calophyllum brasiliense cultivada no Estado do Amapá, nos períodos seco e chuvoso da região. A coleta das amostras ocorreu nos meses de agosto, novembro de 2016 e janeiro de 2017 no município de Mazagão-AP. O sequestro de radicais livres (SRL) foi avaliado pelo método do 2,2-difenil-1-picril-hidrazila (DPPH·) a $60 \mu \mathrm{M}$. Dentre os meses avaliados o que apresentou maior atividade foi o mês de janeiro de 2017 ( IC $_{50} 2,89 \pm 0,10 \mu \mathrm{g} / \mathrm{mL}$ ), em comparação aos meses de agosto ( $\mathrm{IC}_{50} 6,91 \pm 0,22 \mu \mathrm{g} / \mathrm{mL}$ ) e novembro ( $\mathrm{IC}_{50} 32,99 \pm 0,02$ $\mu \mathrm{g} / \mathrm{mL}$ ), que apresentou menor atividade. Os resultados obtidos revelaram que para obter um extrato a partir das cascas de $C$. brasiliense com maior atividade antioxidante, o melhor período de coleta é o período chuvoso.
\end{abstract}

\section{INTRODUÇÃO}

O elevado potencial da biodiversidade vegetal da região Amazônica vem motivando um maior interesse de pesquisas científicas neste bioma. É importante chamar a atenção para o fato de que, embora o foco sejam plantas da Amazônia com interesse terapêutico ou uso medicinal, estas plantas também podem ser caracterizadas como fontes de novas espécies químicas (NEQs) para os mais diversos fins. (BOLZANI, 2016; SILVA, 2011).

Dentre as aplicações industriais para as NEQs deve ser destacado o uso como antioxidante, que é muito necessário na indústria alimentícia. A oxidação de um alimento é comumente definida como a reação com oxigênio ou outras substâncias com a perda de elétrons em sua estrutura molecular, alterando assim suas características (ALVES, 2010).

O oxigênio molecular é pouco reativo, porém em meio orgânico há a formação de espécies químicas derivadas do oxigênio, também chamadas de espécies reativas do oxigênio (EROs), na maioria radicais livres, que pode ser definidos como moléculas ou átomos que contém um ou mais elétrons não pareados, os radicais livres apresentam a característica de serem intensamente reativos e o seu excesso nos alimentos pode comprometer desfavoravelmente a manutenção de suas características. Assim, há a necessidade de adição 
de moléculas antioxidantes para inibir ou retardar a ação do excesso de radicais livres (BERGAMASCHI, 2010).

O uso de antioxidantes em alimentos é amplo, estes compostos podem ser naturais ou sintéticos. O uso de antioxidantes sintéticos vem sendo reduzido, por haver comprovações da associação do uso destes compostos sintéticos com a prevalência de neoplasias. Assim, os benefícios ocasionados à conservação de alimentos por meio de substâncias bioativas, com destaque para os antioxidantes naturais, que agem sobre os radicais livres têm se tornado grande objeto de estudos, visto que os antioxidantes são capazes minimizar consideravelmente a oxidação de outra substância desde que esteja em menor concentração em relação à substância oxidável em questão, impossibilitando assim os malefícios causados em virtude da ação dos radicais livres e em geral apresentam maior segurança no uso contínuo (MILANI et al., 2012; ALVES, 2010; SILVA, 2011).

A espécie Calophyllum brasiliense também é conhecida como jacareúba. Seu crescimento se dá em água e até em áreas de mangue. A aplicabilidade da espécie no setor econômico passa pela fabricação de móveis, pisos, mastros de embarcações e carpintaria em geral, medicinal com a extração do látex, uso ornamental e outros. Todavia, apesar dos inúmeros usos são poucos os estudos sobre a atividade antioxidante e variação sazonal desta espécie em ambiente amazônico (NAVARRO, 2007; PIOTTO et al., 2003; BOTREL et al., 2006).

O estudo de sazonalidade contribui para avaliação da variação do teor de ativos da planta e sua influência na atividade biológica frente a diferentes variações ambientais durante o ano, sendo possível estabelecer o melhor período de coleta do material botânico para uso terapêutico (MORAIS, 2016). Baseando-se nesses fatores, o presente trabalho teve como objetivo o monitoramento sazonal da atividade de sequestro do radical livre DPPH $\cdot$ das cascas da espécie Calophyllum brasiliense cultivada no Estado do Amapá, nos períodos seco e chuvoso da região.

\section{MATERIAL E MÉTODOS}

\subsection{Obtenção e preparo dos extratos}

Em parceria com o Instituto de Pesquisas Cientificas e Tecnológicas do Estado do Amapá (IEPA) a coleta, herborização e identificação foram realizadas pelo corpo técnico do Instituto. As amostras foram coletadas nos meses de agosto, novembro de 2016 e janeiro de 2017 no município de Mazagão-AP, caracterizando assim o período de seca e início do período chuvoso na região. Após a coleta as cascas foram levadas ao Laboratório de Química Orgânica e Bioquímica da Universidade do Estado do Amapá (UEAP), para os devidos procedimentos de preparação dos extratos. O preparo dos extratos ocorreu através da fragmentação das cascas da espécie e maceração em etanol:água (70:30 p/p) por 4 dias/temperatura ambiente/agitações periódicas e banho ultrassom por 15 minutos/dia. Após filtração em papel-filtro, o volume dos filtrados foi mensurado e concentrado em rotaevaporador $\left(40^{\circ} \mathrm{C} /\right.$ pressão negativa). Os extratos hidroalcoólicos obtidos foram o objeto de estudo para a avaliação da variação sazonal da atividade de sequestro do radical livre DPPH· da espécie Calophyllum brasiliense cultivada no Estado do Amapá. 


\subsection{Determinação da atividade de sequestro do radical livre DPPH}

O sequestro de radicais livres (SRL) foi avaliado pelo método do 2,2-difenil-1-picrilhidrazila (DPPH·) a $60 \mu \mathrm{M}$, que é bastante difundido no estudo dos antioxidantes naturais por se tratar de um método simples e intensamente sensível, o mesmo é baseado no descoramento de uma solução de DPPH. (cor violeta) que ao receber um átomo de hidrogênio forma estruturas de ressonância estáveis, passando para uma cor de tonalidade amarelada (NASCIMENTO et al., 2011). As alíquotas de 0,1 mL das amostras de todos os extratos obtidos da coleta sazonal, nas concentrações de $0,5-50 \mu \mathrm{g} \mathrm{mL} \mathrm{m}^{-1}$ foram adicionadas a $3,9 \mathrm{~mL}$ da solução de DPPH. e incubada na temperatura ambiente por $30 \mathrm{~min}$. A leitura da absorvância de cada amostra foi realizada em espectrofotômetro a $515 \mathrm{~nm}$. O controle foi preparado substituindo a amostra pelo mesmo volume de metanol. Todos os ensaios foram realizados em duplicata. $\mathrm{O}$ efeito do sequestro de radical (\%) foi calculado usando a seguinte equação: Efeito do sequestro do radical $(\%)=(\mathrm{A} 0-\mathrm{A}) \times 100 / \mathrm{A} 0$ onde A0 é a absorvância do DPPH. (controle) e A é a absorbância da amostra mais DPPH. E, após os resultados de porcentagem de sequestro do radical livre foram calculados os valores da $\mathrm{IC}_{50}$ por regressão linear. As análises estatísticas foram realizadas no software Graphpad Prism 6.0 ${ }^{\circledR}$.

\section{RESULTADOS E DISCUSSÃO}

Os resultados do sequestro do radical livre DPPH. pelos compostos químicos dos extratos hidroalcoólicos das cascas de Calophyllum brasilienses coletadas em agosto e novembro de 2016 e janeiro de 2017 foram expressos em $\mathrm{IC}_{50}(\mu \mathrm{g} / \mathrm{mL})$, como apresentados na Figura 1. E houve variação sazonal estatisticamente significante entre as atividades de sequestro do radical livre avaliadas. Variação sazonal esta que foi acentuada pelo final do período seco na região, caracterizado por pouca ou nenhuma precipitação pluviométrica, e se estende dos meses de julho a dezembro (SANTOS; CUNHA \& CUNHA, 2014).

Dentre os meses avaliados o que apresentou maior atividade foi o mês de janeiro de 2017 ( $\mathrm{IC}_{50} 2,89 \pm 0,10 \mu \mathrm{g} / \mathrm{mL}$ ), em comparação aos meses de agosto $\left(\mathrm{IC}_{50} 6,91 \pm 0,22 \mu \mathrm{g} / \mathrm{mL}\right.$ ) e novembro ( $\mathrm{IC}_{50} 32,99 \pm 0,02 \mu \mathrm{g} / \mathrm{mL}$ ), que apresentou menor atividade. Segundo Araújo et al. (2015), estes resultados apontam que a baixa atividade pode estar correlacionada ao baixo teor de polifenóis. 
Figura 1 - Capacidade de sequestro de radicais livres (SRL) 2,2-difenil-1-picril-hidrazila (DPPH·) a $60 \mu \mathrm{M}$ das cascas de Calophyllum brasiliense coletadas nos meses de agosto, novembro de 2016 e janeiro de 2017 no município de Mazagão-AP, caracterizando assim o período de seca e início do período chuvoso na região.

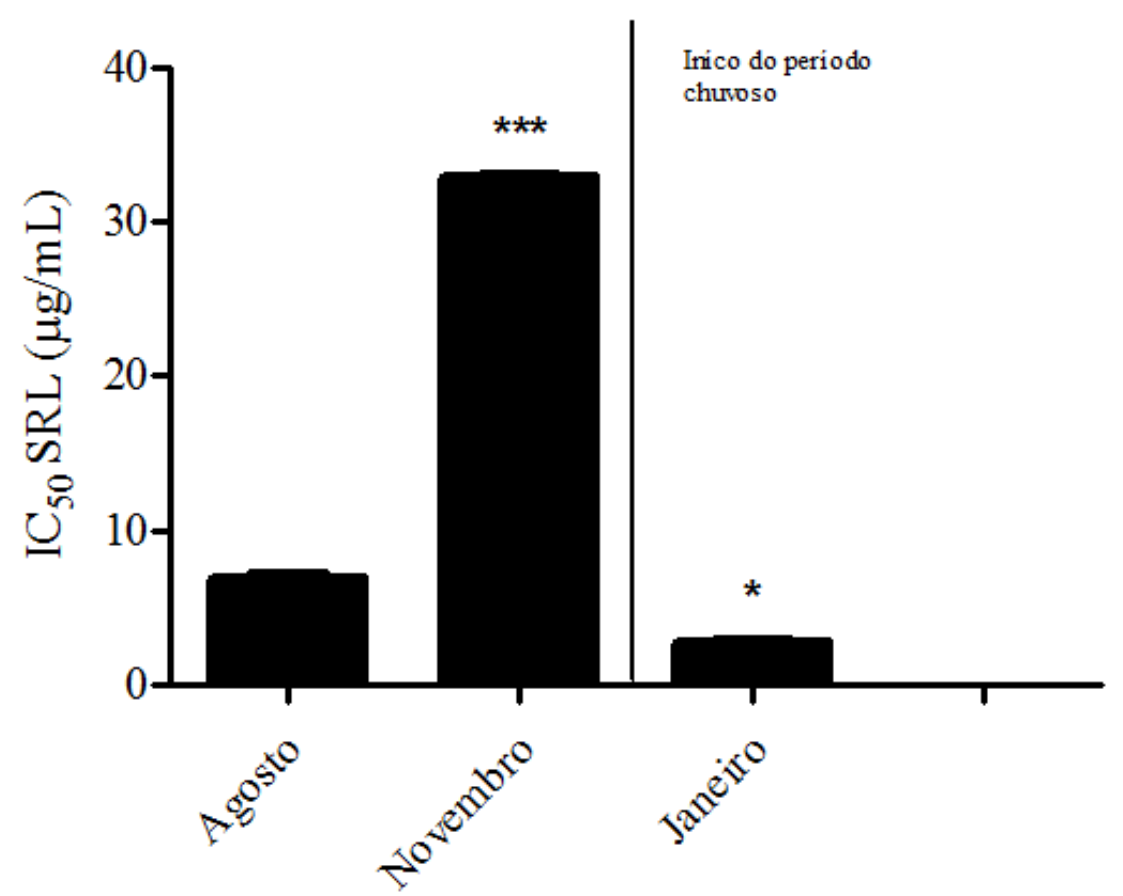

Resultados expressos em média \pm desvio padrão $(\mathrm{n}=2)$ dos valores da concentração inibitória $50 \%$ ( $\mathrm{IC}_{50}$ ) obtidas por regressão linear. * $p<0,05 ; * * p<0,01 \mathrm{e} * * * p<0,001$.

Após a análise dos resultados obtidos para as amostras de Jacareúba ( $C$. brasiliense) foi observado que o mês de janeiro, ou início do período chuvoso, apresentou maior atividade de sequestro do radical DPPH., assim este período é provavelmente a melhor época do ano para realizar a coleta das cascas e obtenção dos extratos. Com a continuação dos experimentos e obtenção de resultados para mais meses, será possível realizar uma correlação entre as variáveis ambientais (temperatura, índice pluviométrico e radiação global) com o potencial antioxidante dos extratos provenientes das cascas de $C$. brasiliense estabelecida por meio da utilização correlação linear de Pearson.

O trabalho corrobora com o fato da variação de temperatura, exposição solar e quantidade de água, poderem afetar de maneira significativa a matéria-prima e consequentemente, a bioatividade das plantas; se faz necessário a constância dos princípios ativos de uma planta, para que possa ser fonte de NEQs, assim é necessário estimar o período de coleta (MORAIS, 2016).

\section{CONCLUSÃO}

Os resultados obtidos revelaram que para obter um extrato a partir das cascas de $C$. brasiliense com maior atividade antioxidante, o melhor período de coleta é o período chuvoso. Este projeto contribui com o desenvolvimento de pesquisas e inovação em plantas e com a valoração de plantas nativas do Bioma Amazônico. 


\section{AGRADECIMENTO}

Os autores agradecem à Universidade do Estado do Amapá pelo apoio fornecido ao trabalho e ao Instituto de Pesquisas Cientificas e Tecnológicas do Estado do Amapá pelo fornecimento das amostras a este projeto vinculadas.

\section{REFERÊNCIAS BIBLIOGRÁFICAS}

ALVES, C. Q; DAVID, J. M.; DAVID, J. P.; BAHIA, M. V.; AGUIAR, R. M. Métodos para determinação de atividade antioxidante in vitro em substratos orgânicos. Quíica Nova. v. 33, n.10, 2010.

ARAÚJO, V. A. P de .; NUNES, A. R.; LUCAS, R.; SILVA, G. A da. Total flavonoid content for standardization of amazonian commercial plant extracts. In: International conference of chemical and biochemical engineering, 2015, Paris. Anais ... Paris, 2015.

BERGAMASCHI, K. B. Capacidade antioxidante e composição química de resíduos vegetais visando seu aproveitamento. 2010. 97 f. Dissertação (Mestrado em ciências) - Escola Superior de Agricultura “Luiz de Queiroz”, Universidade de São Paulo, Piracicaba, 2010.

BOLZANI, V. da S. Biodiversidade, bioprospecção e inovação no Brasil. Ciência e Cultura, v. 68, n. 1, p. 04-05, 2016.

BOTREL, M. C. G.; de SOUZA, A. M.; de CARVALHO, D.; PINTO, S. I. do C.; MOURA, M. C. de Oliveira.; ESTOPA, R. A. Caracterização genética de Calophyllum Brasiliense Camb. em duas populações de mata ciliar. Sociedade de Investigações Florestais. v. 30, n. 5, p. 821-827, 2006.

MILANI, L. I. G.; TERRA, N. N.; FRIES, L. L. M.; CICHOSKI, A. J.; REZER, A. P. S.; BACKES, A. M.; PARODIA, C. G. Atividade antioxidante e antimicrobiana in vitro de extratos de caqui (Diospyros kaki L.) cv. Rama Forte. Brazilian journal food technology. v. 15, n. 2, p. 118-124. 2012.

MORAIS, N. de A. Monitoramento sazonal da atividade antioxidante das folhas de Erythroxylum suberosum A. St.-Hil.: correlação com o teor de hiperosídeo e isoquercitrina. 2016. 91 f. Dissertação de Mestrado. Universidade de Brasília. Brasília, Distrito Federal. 2016.

NASCIMENTO, J. C.; LAGE, L. F. O.; CAMARGOS, C. R. D.; AMARAL, J. C.; COSTA, L. M.; SOUSA, A. N.; OLIVEIRA, F. Q. Antioxidant determination activity by DPPH method and assay for total flavonoids in leaves extracts of Bauhinia variegata L. Revista Brasileira de Farmácia. v. 92, n. 4, p. 327-332, 2011.

NAVARRO, E. C. Viabilidade econômica do Calophyllum brasiliense (Guanandi). Revista Científica Eletrônica de Engenharia Florestal. v. 9, n. 9, 2007. 
PIOTTO, D.; MONTAGNINI, F.; UGALDE, L.; KANNINEN, M. A. Grow than deffect soft hinning of mixed and pure plantations with native trees in humid tropical Costa Rica. Forest Ecology and Management. v.177, p. 427-439, 2003.

SILVA, M. G. F. Atividade antioxidante e antimicrobiana in vitro de óleos essenciais e extratos hidroalcóolicos de manjerona (Origanum majorana L.) e manjericão (Ocimum basilicum L.). 2011. 70 f. Trabalho de conclusão de curso (Bacharelado em Química) Universidade Tecnológica Federal do Paraná, Paraná, Pato Branco, 2011.

SILVA, T. F.; DE OLIVEIRA, A. B. Plantas leishmanicidas da Amazônia Brasileira: uma revisão. Revista Fitos Eletrônica. v. 10, n. 3, p. 341-365, 2017. 